\title{
Uniform particle distribution by a newer method in composite metal of $\mathrm{Al} / \mathrm{SiC}$
}

\author{
Ajay kumar sahu, Payodhar padhi* \\ Department of mechanical engineering ,Orissa engineering college, BPUT, India \\ * Department of mechanical engineering, Konark institute of science \& Technology, BPUT, India.
}

\begin{abstract}
Preparation of composites of metal with ceramic particle reinforced through the casting process is not uniform because of poor wet ability. The major difficulty is to get a uniform distribution of reinforcement especially in higher volume fractions. An innovative method of producing cast composites is tried in present study to overcome this problem we need homogeneity of matrix. The method involves multi axis rotation of liquid aluminum and silicon carbide particulates packed in a steel pipe inside a rotating drum. Up to $65 \%$ volume of the metal (aluminum)is incorporated by SIC by this technique. Physical Properties like hardness, micro hardness, densities and microstructures have been studied. The distribution of particles as well the mechanical properties are better as compared to that of stir cast composites with similar volume fraction of silicon carbide reinforcement. The composite with 65-volume percentage of silicon carbide of particulates showed a Rockwell Hardness value of 67Rb.In few locations the microstructure showed a non-uniform distribution which can be neglected. There were segregation of silicon carbide particles at a particular location and the hardness obtained there was much higher. The particle distribution is a result of the combined influence of random mixing of particles and liquid aluminum and the solidification pattern obtained.
\end{abstract}

Key word: Multi axis rotation, microstructure, MMC, Al- SIC matrix

\section{Introduction}

High bulk and rigidity modulus, high mechanical strength, high wear resistance, low thermal and electrical conductivity and low sensitive to temperature variations of metal matrix composites (MMC) has drawn high attention for applications from high structural members to electronic packaging. General type of composites lacks behind the Particle reinforced MMCs since they show isotropic behavior. One of the most investigated $\mathrm{MMC}$ combination of $\mathrm{Al} / \mathrm{SiC}$ particulates in a matrix form.

This system has the potential for light and high structural components and low thermal expansion electronic packaging applications (Clyne, 1993 and Duralcan, 1996). Metal matrix composites can be processed using number of techniques. These techniques can be broadly classified as a) liquid phase techniques b) solid phase techniques c) semi solid techniques (Gupta et al., 1993). In present work an innovative method of producing cast composites has been attempted. The method involves multi axis random rotation (Mishra et al., 1993) of liquid aluminum and Sic particulates enclosed in a steel pipe which is kept inside a rotating spherical drum. The effect of vibration and mould rotation about one axis on the solidifying melt during casting process has been studied by many investigators (Campbell, 1981) with partial success. Centrifugal casting is known to enhance drastic segregation of heavy elements (Rohtgi, 1986) towards the periphery and concentrates lighter elements at the central portion. This study on the other hand is an innovative approach to mould rotation around more than one axis at random. The expected advantages of the application of this technique are to get homogeneity of distribution and improved mechanical properties (Sarath Chandra and Ramesh, 2011).

\section{Materials And Methods}

Materials: Commercial Aluminum was used as matrix material for the present study. The chemical composition of $\mathrm{Al}$ is given in the Table 1. Silicon Carbide particulates were selected as the reinforcement. The composition of $\mathrm{Sic}$ particulates is in (wt \%) in Table 2. Manufacturing process: Multi-axial random rotation technique (Mishra et al., 1993) was used to process the MMC in which a ball mill was used into which a steel cylindrical sample holder was dropped. The steps of preparation of the sample holder for multi-axial rotation are as follows. A steel tube of size $55 \mathrm{~mm}$ internal diameter and $55 \mathrm{~mm}$ length is served as the crucible for melting as well as dies for the casting. Commercially pure aluminum was melted in an electrical resistance pit furnace and cast into cylinders of $55 \mathrm{~mm}$ matching with the internal diameter of the tube. From the height of the die and the volume fraction of silicon carbide in the composite the exact aluminum and silicon carbide needed was estimated. In the first attempt the 
aluminum cylinder was kept at the bottom and rest of the tube was filled with Sic However the attempt was not successful in getting the particles uniformly distributed in the final composite. There was local segregation of particles as seen in micrograph Fig 1(a).In subsequent attempts the aluminum needed was divided into two equal halves and the silicon carbide was put in between the two pieces. Then the tube was sealed by a steel plate welded to the tube at top and bottom. Over the tube as above three metallic mild steel rings are suitably placed and welded giving a spherical out line to the assembly. It was done in order to get the random rotation along multi axis just like that in a ball mill. The closed tube as

prepared above was heated to a temperature of $1000 \mathrm{C}$ in a furnace to ensure complete melting of $\mathrm{Al}$. Then these were charged into a ball mill with a cylindrical drum of length $600 \mathrm{~mm}$ and $450 \mathrm{~mm}$ diameter rotated by a three phase one hp motor at a speed of $50 \mathrm{rpm}$. The ball mill door was closed instantaneously, and the motor was switched on for the drum to rotate. The rotation was continued for 20 minutes to ensure that composite solidified completely inside the mold. Then the assembly was taken out and the MMC ingot is stripped of for further investigations. The cast cylinder so obtained is cut in the middle along the length and breadth for samples to obtained for study of mechanical properties of the composites

\section{Results And Discussions}

Density Measurements: The densities of the aluminum matrix as well as $\mathrm{Al} / \mathrm{SiC}$ samples were measured by Archimedes principle. The sample was collected at random. The results are given in Table 3 . The density of the composite confirms to the expected trend i.e. more the volume fraction of particulates the higher is the density of the composite. This is mainly because of the higher density of the Sic particulates in comparison to $\mathrm{Al}$ metal. There is a variation in density from location to location. However this is not very significant showing that the particle distribution is uniform. Further the increase in density is not proportional to the increase the volume fraction of particles as seen in Fig 2. The increase in density of composite is a result of addition of Sic, which has a higher density. Density is also influenced by the presence porosity. The porosity level in cast composite is appreciable and it is reported to increase with increase in particle content. This is reflected in the density variation with increase in particle content. Hardness Measurements: Table no 4 gives the Rb hardness of composites. The hardness was measured in Rockwell hardness tester at a load of $100 \mathrm{~kg}$ with the suitable indenter as per B scale. Twelve samples of each volume fractions were tested for hardness. Fig3.clearly shows the upward trend of hardness increase with increased volume fraction of Sic particulates in the MMC. The variations of hardness show a trend very similar to the density variation clearly bringing out the influence of porosity in the samples. The hardness values obtained are higher as compared to the stir cast composites indicating that the porosity in the composites produced by the present method is lower. The hardness variation with location is also minimal showing that the particle distribution obtained is uniform. Microstructure: The SEM and optical micrographs are shown in Fig 1 with different volume fractions of $\mathrm{SiC}$ particulates. The micrographs show that there is uniformity of particle distribution as well as good interface between the particle and matrix except for the $10 \%$ volume fraction composite. Fig 1(a) shows the structure of composites obtained in the first set of experiments. It shows segregation of particles in a region .The hardness in this zone was also much higher. Micro hardness: The micro hardness values are shown in Table 5. The micro hardness was measured using LECO, DM -400 Micro hardness tester. Micro hardness measurements were made using a paramedical diamond indenter with a facing angle of 136 degree, 25gf indenting load and load dwell time of $15 \mathrm{sec}$ on the matrix and at a specific distance $~ 15$ micro meter from the interface of the interface of the SiC particulates and the matrix. The hardness values vary in the region around $\mathrm{SiC}$ particulate matrix interface depending on distance from interface. However the nature variation does not show any clear trend. There is an increase in the micro hardness of the matrix with addition of the particles. The hardness increased from $28 \mathrm{Hv}$ to around $38 \mathrm{Hv}$ with addition of particles. However the volume fraction of particles does not have any significant influence of the matrix micro hardness. Increase in micro hardness of the matrix is possibly due to the higher dislocation density levels generated because of the presence of silicon carbide particle structure. There is large change in the micro hardness of the inter face with increase in the volume fraction of the particle. The hardness of the particles also varies with location.

Table 1, compositions of pure commercial aluminum

\begin{tabular}{|l|l|l|l|l|}
\hline element & Fe & $\mathrm{Mg}$ & $\mathrm{Si}$ & Al \\
\hline $\mathrm{Wt} \%$ & $\mathbf{2 . 9 6}$ & $\mathbf{0 . 4 3}$ & $\mathbf{0 . 2 6}$ & Balance \\
\hline
\end{tabular}

Table-2 ;-composition of sic

\begin{tabular}{|l|l|l|l|l|l|}
\hline Element & $\mathrm{C}$ & $\mathrm{SiO2}$ & $\mathrm{Al}$ & $\mathrm{Fe}$ & SiC \\
\hline $\mathrm{Wt} \%$ & $\mathbf{1 . 1 6}$ & $\mathbf{0 . 6 5}$ & $\mathbf{0 . 3 1}$ & $\mathbf{0 . 0 2}$ & Balance \\
\hline
\end{tabular}


Table 3. Density Measurement (material ) A/SiC \%

\begin{tabular}{|l|l|l|l|l|l|l|}
\hline $\begin{array}{l}\text { Fraction of Sic } \\
\text { particle in( v) } \%\end{array}$ & \multicolumn{3}{|l|}{ Density in gm /cm2 } & $\begin{array}{l}\text { Average Density in gm } \\
\text { Cm2 }\end{array}$ \\
\hline 0 & 2.69 & 2.68 & 2.69 & 2.69 & 2.68 & 2.69 \\
\hline 10 & 2.70 & 2.71 & 2.74 & 2.74 & 2.76 & 2.73 \\
\hline 15 & 2.72 & 2.79 & 2.78 & 2.76 & 2.77 & 2.75 \\
\hline 20 & 2.78 & 2.81 & 2.79 & 2.77 & 2.82 & 2.79 \\
\hline 30 & 2.85 & 2.88 & 2.79 & 2.86 & 2.87 & 2.81 \\
\hline 65 & 2.87 & 2.98 & 2.87 & 2.96 & 2.98 & 2.93 \\
\hline
\end{tabular}

Table 4;-hardness measurements (Rockwell)(Material A/SiC $\mathbf{C}_{\mathrm{p}}$ )

\begin{tabular}{|l|l|l|}
\hline Volume fraction & Hardness $($ Rb) & Average (Rb) \\
\hline 0 & $18,2019,18,20,21,19,18,20,17,19,20$ & 19.0 \\
\hline 10 & $38,47,42,39,49,40,40,41,43,37,46,39$ & 41.7 \\
\hline 20 & $46,59,39,52,55,42,51,52,49,49,43,52$ & 49.0 \\
\hline 30 & $66,58,47,68,59,54,53,55,57,56,54,55$ & 56.8 \\
\hline 65 & $71,70,57,60,79,70,69,69,74,80,54,59$ & 67,6 \\
\hline
\end{tabular}

Table 5;-Micro hardness measurements

\begin{tabular}{|l|l|l|l|l|}
\hline Load & $\begin{array}{l}\text { Volume } \\
\text { fraction }\end{array}$ & Matrix*(Hv) & Interface**Hv) & Particle (Hv) \\
\hline 25gf & 0 & 28 & & \\
\hline 25gf & 10 & 37 & 47 & 2264 \\
\hline 25 gf & 30 & 39 & 75 & 3079 \\
\hline 25 gf & 65 & 38 & 113 & 2560 \\
\hline
\end{tabular}

(a) $10 \%$ volume fraction $(60 \mathrm{x})$

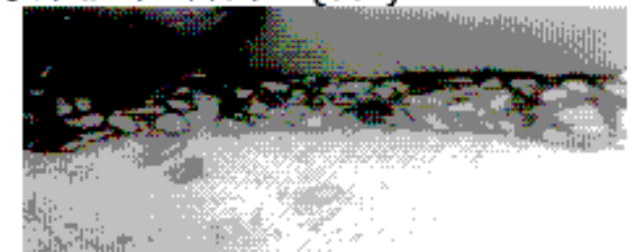

(c) $20 \%$ volume fraction

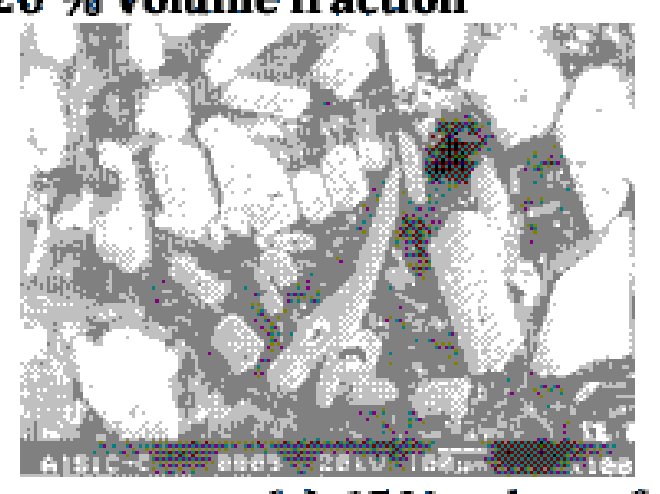

(b) $10 \%$ volume fraction

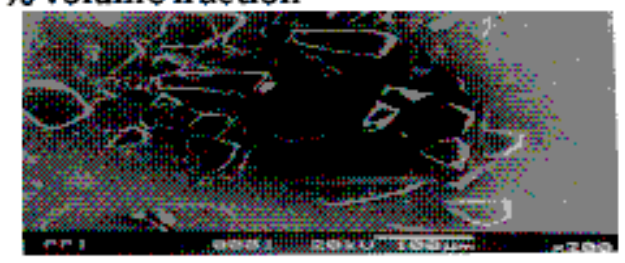

(d) $30 \%$ volume fraction

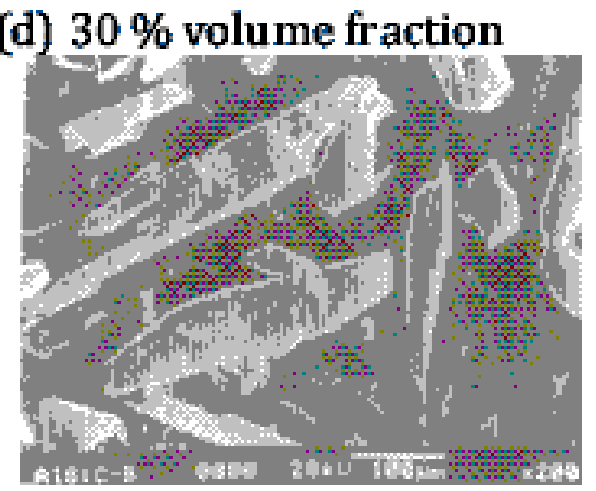

(g) $65 \%$ volume fraction

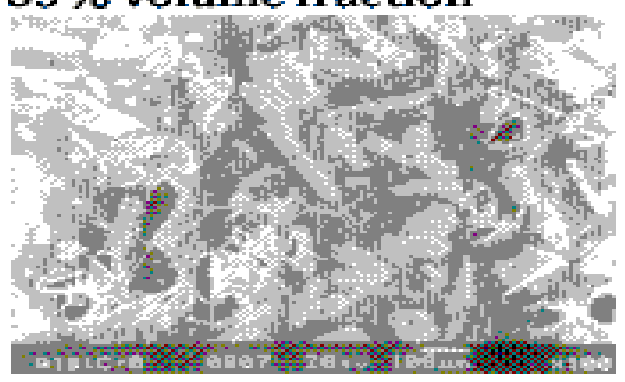

Fig 1-Micrograf illustrating the particle distribution in $\mathrm{Al} / \mathrm{SiC}$ composites 
(a) $10 \%$ volume fraction $(60 x),(b) 10 \%$ volume fraction, (c) $20 \%$ volume fraction, (d) $30 \%$ volume fraction (g)65\% volume fraction

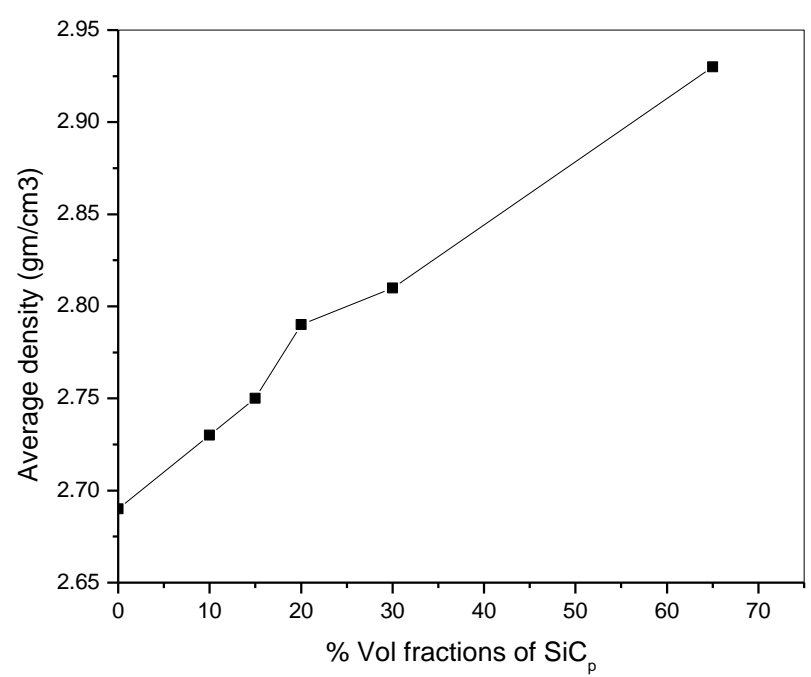

Fig 2: Variation in densities as a function of volume fraction

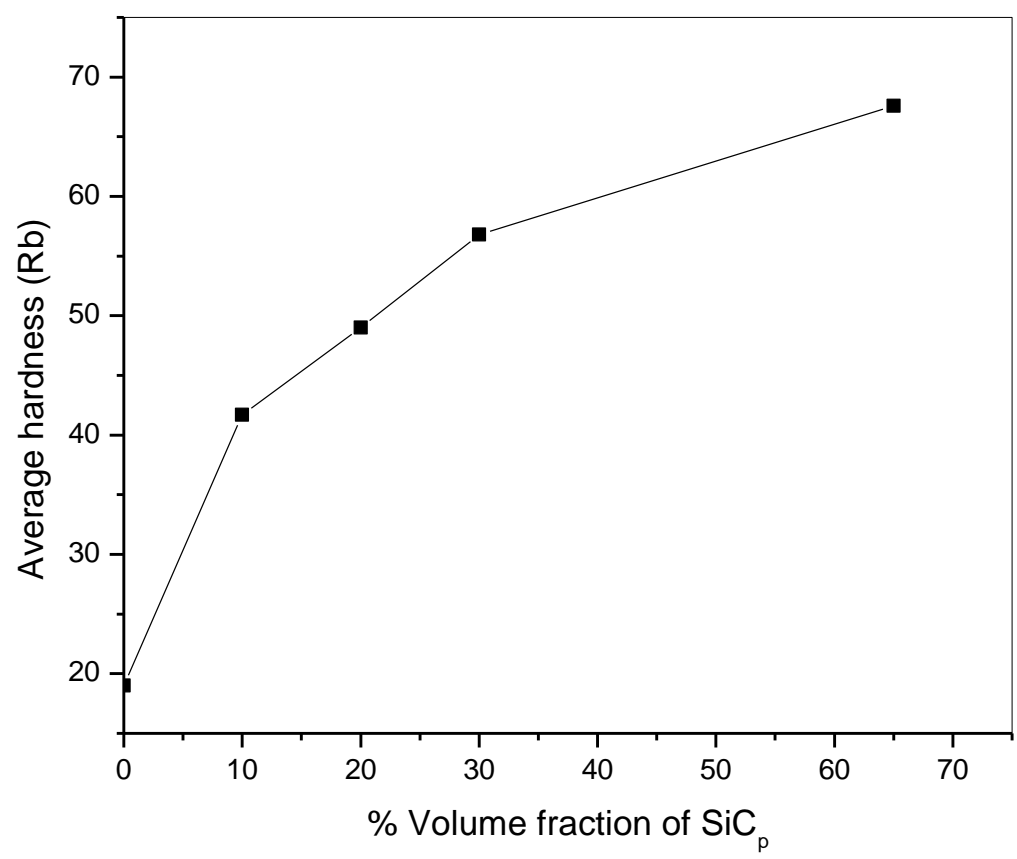

Fig 3: Variation in hardness as a function of volume fraction

\section{Conclusions}

1: Multi axis rotation can be successfully used to get Aluminum matrix silicon carbide particle reinforced composites up to 65-volume percentage of particles. In most cases the particle distributions obtained is uniform. 2: There is a significant increase in hardness of the composites prepared by this technique. Rate of increase in hardness with particulate addition decrease possibilities due to increase in porosity level.

3: The micro hardness of the matrix increases with addition of particles. However increase in particles dose not influences this value significant.

4: The micro hardness at the interface increases significantly with increases in particulate addition 


\section{References}

[1]. Padhi ,.P. PhD Thesis, 2006

[2]. C.M.Milliere and M.Surry. Mat Sc \&Tech, 4, 41(1998)

[3]. "Duralcan Aluminium MMCs “ Duralcan(1994)

[4]. J.Campbell, International Metals Reviews 26(2): 71-108 (1981)

[5]. M.Gupta,T.S Srivastan,F.A Mohammad and E.J.Lavernia, J.Mat.Sc .28,2245 (1993)

[6]. Misra .K. Asoka Metastable Structures (Principle, Design \& Appl) Ind-US.w/s-Goa 111-114(1993)

[7]. P.K.Rohtgi,R.Asthna and S.Das International Metals Review 31 (3): 115-139.(1986)

[8]. T.W Clyne and P.J Withers,An introduction to MMCs, Cambridge University Press, Cambridge, U.K (1993). 